\title{
OPENING ADDRESS
}

\author{
Dr. Y. TAZIMA
}

Ladies and Gentlemen:

It is my very great pleasure to welcome all of you to this International Symposium on Genetic Effects of Space Environment.

Ever since the pioneer Russian space flights, biological observations and experiments have been carried out. Many of the results have suggested that some feature or features of the space flight environment might produce genetic effects, either alone or in combination with the radiation encountered during flight. The magnitude of some of the effects observed have led some to postulate a synergism between such factors as "weightlessness" or vibration and radiation. Such effects are not only of obvious practical interest for manned space flight, but are also of great theoretical interest to geneticists.

Russian scientists have reported a large number of experimental results and observations on this subject, both from material flown on various space craft, and from parallel investigations carried out on the ground. American workers have also carried out such investigations including, most recently, a series of experiments carried on Biosatellite II.

It was Dr. Arnold Sparrow, of the Brookhaven National Laboratory in the United States, and one of the scientists with experiments on the Biosatellite, who suggested that a Symposium might be held on genetic effects of space flight during the XII International Congress of Genetics. He pointed out that in spite of various meetings in the past, such as the COSPAR meeting held here in Japan last spring, there never has been a real opportunity for the workers from Russia and the United States to assemble together and discuss their work. The Genetics Congress not only presented this opportunity, but also assured that interested geneticists from all nations would have a chance to participate in the discussions.

Unfortunately, Dr. Sparrow's suggestion came too late for this Symposium to be included among the regular sessions of the Congress. The Organizing Committee felt it was important enough, however, so that this Symposium was set up as a concurrent meeting, to be held on the only day available. This is why you are all here on a sunday, instead, perhaps, of enjoying a pleasant excursion to Nikko or Hakone. It is really unfortunate that Dr. Sparrow, who worked so herd to organize this Symposium, was at the last minute prevented by ill health from attending himself.

Now, without further comment, it is my pleasant duty to turn the proceedings over to our Chairmen for this morning's session, Drs. R. F. Kimball and E. N. Vaulina. 